\title{
Quasi-Static Axial Crushing Behavior of Honeycomb-Filled Thin-Walled Aluminum Tubes
}

\author{
Levent Aktay ${ }^{1,}$, Cem Çakıroğlu ${ }^{2}$ and Mustafa Güden ${ }^{*, 2}$
}

\author{
${ }^{I}$ German Aerospace Center, Institute of Structures and Design, Pfaffenwaldring 38-40, D-70569, Stuttgart, Germany \\ ${ }^{2}$ Department of Mechanical Engineering and Center for Materials Research, Izmir Institute of Technology, Gulbahce \\ Koyu, Urla, Izmir, Turkey
}

\begin{abstract}
The experimental and numerical quasi-static crushing behaviors of Nomex ${ }^{\mathrm{TM}}$ honeycomb-filled thin-walled $\mathrm{Al}$ tubes were investigated. The honeycomb filler was modeled using a unit cell model. The numerical model and experimental results have shown that, $6.4 \mathrm{~mm}$ and $4.8 \mathrm{~mm}$ cell size honeycomb filling had no effect on the deformation mode (diamond); however $3.2 \mathrm{~mm}$ cell size honeycomb filling changed the deformation mode to mixed/concertina. Honeycomb filling was also shown to increase the specific energy absorption of filled tubes over that of Al tube. The specific energy absorption of honeycomb filling was further compared with those of tube wall thickening and Al closedcell foam filling.
\end{abstract}

Keywords: Honeycombs, Honeycomb-filled tubes, Finite element modeling.

\section{INTRODUCTION}

The crush energy absorbing structures have been generally constructed in tubular/columnar forms that absorb the deformation energy nearly at a constant load. The constant load energy absorption results from the progressive folding mechanism of thin walls, which was first analytically formulated by Alexander [1] in 1960. Since Alexander, extensive experimental and numerical investigations have been performed in order to understand and improve the energy absorption capabilities of tubular structures. In recent years, the lightweight foam filling has been taken considerable interest due to their potentials of enhancing/improving the energy absorption capabilities of tubular structures. A short review of previous studies on the crushing behavior of empty and foam-filled tubular structures can be found in [2] and it has been noted that lightweight honeycomb filling has not been extensively studied as foam filling. Santosa and Wierzbicki [3] investigated the axial crushing behavior of $\mathrm{Al}$ honeycomb and Al foam-filled box columns. It was shown that Al honeycomb filling of the box columns was more efficient in specific absorbed energy (SAE) than both Al foam filling and the column wall thickening (the mass of empty column increased to that of the filled-tube). The bending collapse of $\mathrm{Al}$ honeycomb and Al foam-filled box columns was numerically and experimentally investigated by the same authors [4]. Al foam and honeycomb filling of the columns increased the bending strength and a further improvement was achieved when the filler was bonded to the tube wall.

*Address correspondence to this author at the Department of Mechanical Engineering and Center for Materials Research, Izmir Institute of Technology. Gulbahce Koyu, Urla, Izmir 35430, Turkey; Tel: +90 232 7506779; Fax: +90 232 7507890; E-mail: mustafaguden@iyte.edu.tr

${ }^{\S}$ Currently at Daimler AG, Sindelfingen, Germany.
The SAEs of the filled columns were also found to be higher than those of the column wall thickening. Santosa and Wierzbicki [5] further investigated Al honeycomb and Al foam double-wall sandwich Al columns. The double-wall sandwich columns were shown to be energetically more efficient than the single wall columns and resulted in 40$60 \%$ and $35-40 \%$ weight savings for honeycomb and foamfilling, respectively. In a recent study of Zarei and Kröger [6], the axial and oblique impact crash responses of empty and $\mathrm{Al}$ honeycomb-filled square tubes have been analyzed using multi design optimization. Honeycomb filling of tubes was noted in the same study as an alternative way of increasing the energy absorption capacity of the empty tubes, agreeing with the previous work of Wierzbicki and Santosa [4].

The common point noted in the numerical part of the abovementioned studies was that the mechanical properties of honeycomb were homogenised in the transverse, longitudinal and width directions. The homogenized models seem to be quite practical in honeycomb modeling, but a classical honeycomb material has a uniform hexagonal cell structure, which is characterized by the cell wall material, unit cell size, cell wall thickness and density. The crushing strength is function of the geometrical and the material properties. For these, some investigations tend to use micromechanical modeling approach, in which each core shell is modeled with shell elements. These models essentially represent the real geometry of the honeycomb structures more precisely than the homogenized models.

The present study focuses on the modeling of the crushing behavior of honeycomb-filled thin-walled Al tubes. Although unit cell modeling of honeycomb materials have been studied extensively in various structural components, part of which was explained above, its use as filler in thinwalled tubes has not been investigated yet. The results of this study were further compared with those of foam-filled tubes 

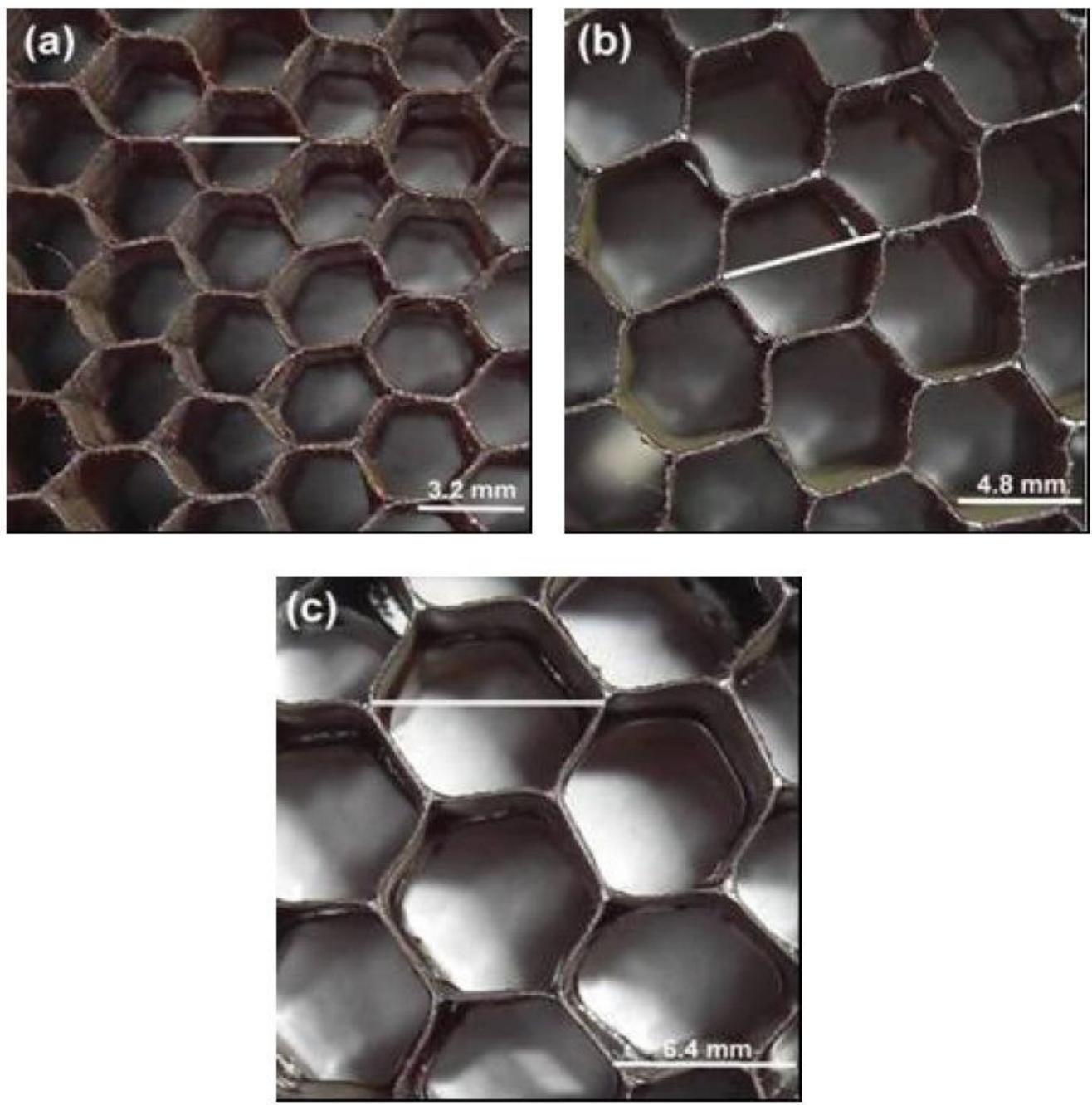

Fig. (1). Top sections views of the honeycomb sheets; (a) 3.2, (b) 4.8 and (c) $6.4 \mathrm{~mm}$ cell size.

in order to assess any advantages of the honeycomb filling in tubular structures.

\section{EXPERIMENTAL STUDY}

Three types of Nomex ${ }^{\circledR}$ honeycombs supplied by EuroComposites were used to fill thin-walled Al tubes. The cell size of the honeycombs were 3.2, 4.8 and $6.4 \mathrm{~mm}$ and the cell wall thickness varying between 0.09 and $0.15 \mathrm{~mm}$ (Fig. 1).

The densities of the honeycombs were however the same, $48 \mathrm{~kg} \mathrm{~m}^{-3}$. Deep-drawn thin-walled Al tubes $(99.7 \% \mathrm{Al})$ were produced by METALUM Company of Turkey and received $25 \mathrm{~mm}$ in diameter and $25.4 \mathrm{~mm}$ in length with 0.29 $\mathrm{mm}$ wall thickness. Before the insertion the honeycomb fillers into Al tubes, the surfaces of the Al tubes were cleaned with acetone. In the filled tubes, two layers of the same type Nomex ${ }^{\mathrm{TM}}$ honeycombs were glued using Bison ${ }^{\mathrm{TM}}$ epoxy in order to increase the thicknesses of honeycomb core $(12.7 \mathrm{~mm})$ to that of the tube $(25.4 \mathrm{~mm})$. The fillers were then core drilled in the thickness direction. During insertion of the core-drilled honeycomb fillers into the Al tubes, the fillers were bonded to the tube walls using the same epoxy-based bonding agent. After bonding, the excess amount of bond agent was cleaned with alcohol. The weights of empty and filled tubes and honeycomb fillers were measured before the compression testing. The compression tests were also applied to the honeycomb samples having the same dimensions with the filler and empty tubes. The axial compression tests were performed at a cross-head speed of $25 \mathrm{~mm} \mathrm{~min}^{-1}$ corresponding to a strain rate of $1.64 \times 10^{-2} \mathrm{~s}^{-1}$ in a Schmadzu AG-I Test Machine. At least five tests were performed for each group of the samples prepared.

\section{NUMERICAL STUDIES}

Geometrical models of honeycomb filling and Al tube elements were created in the finite element program ANSYS $^{\mathrm{TM}}$. The honeycomb fillers were discretized using ANSYS $^{\mathrm{TM}}$ Parametric Design Language (Fig. 2).

The parametric nature of the model allows efficiency and flexibility for the further numerical analysis. In the parametrical design code, a rectangular honeycomb plate was first created; then, the final cylindrical honeycomb filling geometry was extruded from the rectangular plate using post-processing. The meshed geometrical models were subsequently exported to PAM-GENERIS ${ }^{\mathrm{TM}}$ in order to set the boundary conditions. The numerical solutions were carried out using the explicit finite element code PAM$\mathrm{CRASH}^{\mathrm{TM}}$ and PAM-VIEW ${ }^{\mathrm{TM}}$ was used as a post-processor. 


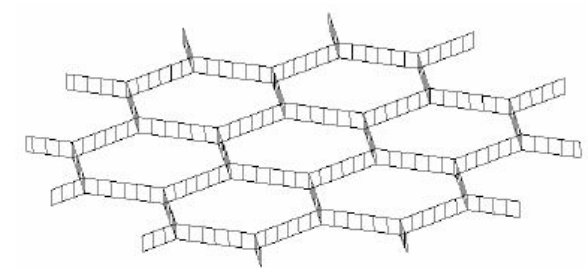

a)

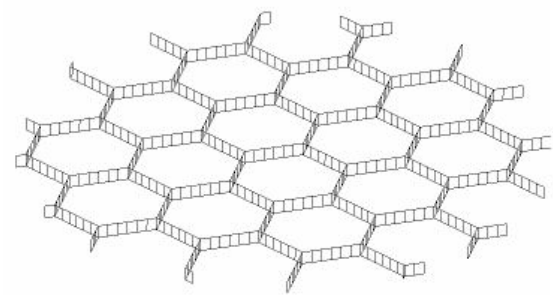

b)

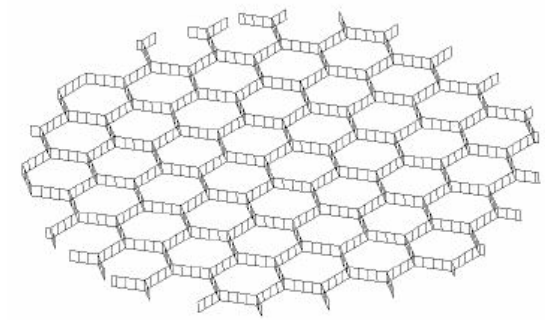

c)

Fig. (2). Discretization of the one layer filler geometries: a) $6.4 \mathrm{~mm}$, b) $4.8 \mathrm{~mm}$ and c) $3.2 \mathrm{~mm}$ cell size honeycombs.

In the micromechanical unit cell model, each honeycomb cell as well as the Al tube was modeled using BelytschkoTsay-4 node-thin shell elements. The bonded cell walls were modeled using double shell elements. Since the honeycomb exhibits anisotropy under compression, a symmetrical model is not applicable. Therefore, the specimens were modeled with actual dimensions. As previously noted [7], the imperfections such as variations in the wall and cell wall junction thicknesses and the cell sizes are very critical in the modeling of cellular structures and unavoidably lead to material stiffness and strength degradations. As the present study aimed at understanding the effect of honeycomb cell sizes on the crushing load and SAE values, the effect of imperfections on the mechanical properties of honeycomb structure was not addressed.

The bottom and top compression test plates were modeled as rigid body with kinematical boundary. The displacements and rotations of the compression test plates were not allowed except the displacement of the upper plate along the vertical axis. The movement of the rigid body was fully determined by the movement of an artificial "node" located at the rigid body center of gravity. Boundary conditions for the rigid body were solely applied to the center of gravity node. Material type 103, the elastic-plastic isotropic thin shell material mode, was used for the tube and honeycomb material. Material type 103 uses an enhanced plasticity algorithm that includes transverse shear effects. It exactly satisfies Hill's criterion [8] and precisely updates the element thickness during the plastic deformation.

Three contact models were used in the modeling: i) a tied contact between the bottom compression test plate and the empty tube, ii) a node-to-segment contact between the top plate and the tube ends and iii) a self-contact between honeycomb and tube wall during plastic deformation (self impacting contact with edge treatment) in order to prevent the interpenetration. The self-contact impact algorithm of type 36 allows all slave segments defined in a given sliding interface. No segment orientation is needed to be specified, since the algorithm automatically detects penetrations and keeps in memory the segment side from which a slave node comes into contact. The self-contact impact algorithm also uses a search algorithm, the so-called 3D Bucket sort algorithm [9] in which the 3D slave surface is subdivided into a number of buckets and the slave nodes are recalculated in terms of bucket coordinates. According to a slave node bucket coordinates, its proximity to slave segments is quickly determined. After the global search phase, an accurate local search algorithm is started.
The interaction between the tube wall and the honeycomb filler was defined via multiple segment-tosegment contact, type 23. Multiple segment-to-segment contact uses an enhanced searching algorithm for detecting penetrations. Based on the each master segment domain box, candidate slave nodes are searched by an efficient sorting method. For a given master segment at every time step, only its candidate nodes are checked for penetrations. Penalty forces are applied to those nodes which are judged to be penetrating the master segment. The bond layer between tube and filler was not included in the numerical model since it causes numerical problems as will be discussed in the next section.

\section{RESULTS AND DISCUSSION}

In order to validate material parameters of the honeycomb material, the quasi-static compression test of the three different densities of honeycombs samples $(25 \mathrm{~mm}$ in diameter and $12.7 \mathrm{~mm}$ in length) were simulated. First, 4.8 $\mathrm{mm}$ cell size specimen was numerically investigated, then the extracted material model parameters were used to model the compression testing of $3.2 \mathrm{~mm}$ and $6.4 \mathrm{~mm}$ cell size specimens. Fig. (3) shows the numerical and experimental load-displacement curves of the honeycombs.

As is expected, $3.2 \mathrm{~mm}$ cell size honeycomb shows the highest crushing load and $6.4 \mathrm{~mm}$ cell size honeycomb the lowest crushing load. It is also noted in Fig. (3) that the model and experimental load values show good correlations with each other until about $60 \%$ deformation. The discrepancy between numerical and experimental load values near the densification region is due to the complex deformation modes resulting from the small size specimen fixing in the model. Fig. (4a-c) show sequentially the numerical model deformations of the $6.4 \mathrm{~mm}, 4.8 \mathrm{~mm}$ and $3.2 \mathrm{~mm}$ cell size honeycomb samples at different percent strains. As is clearly seen in these figures, all samples exhibit a progressive folding mechanism which was fully in accord with the experiments (not shown here).

Fig. (5a, b) show the pictures of the experimentally and numerically deformed empty tubes until about various percent strains, respectively. Empty tubes crush progressively in diamond mode (Fig. 5a), similar to that of numerically compressed empty tubes (Fig. 5b). Fig. (6) shows the load-displacement curves of experimentally and numerical compressed empty tubes. The numerical loaddisplacement curve closely approximates the characteristics of the experimental load-displacement curves of empty tubes: the load initially increases to a maximum peak-load, 


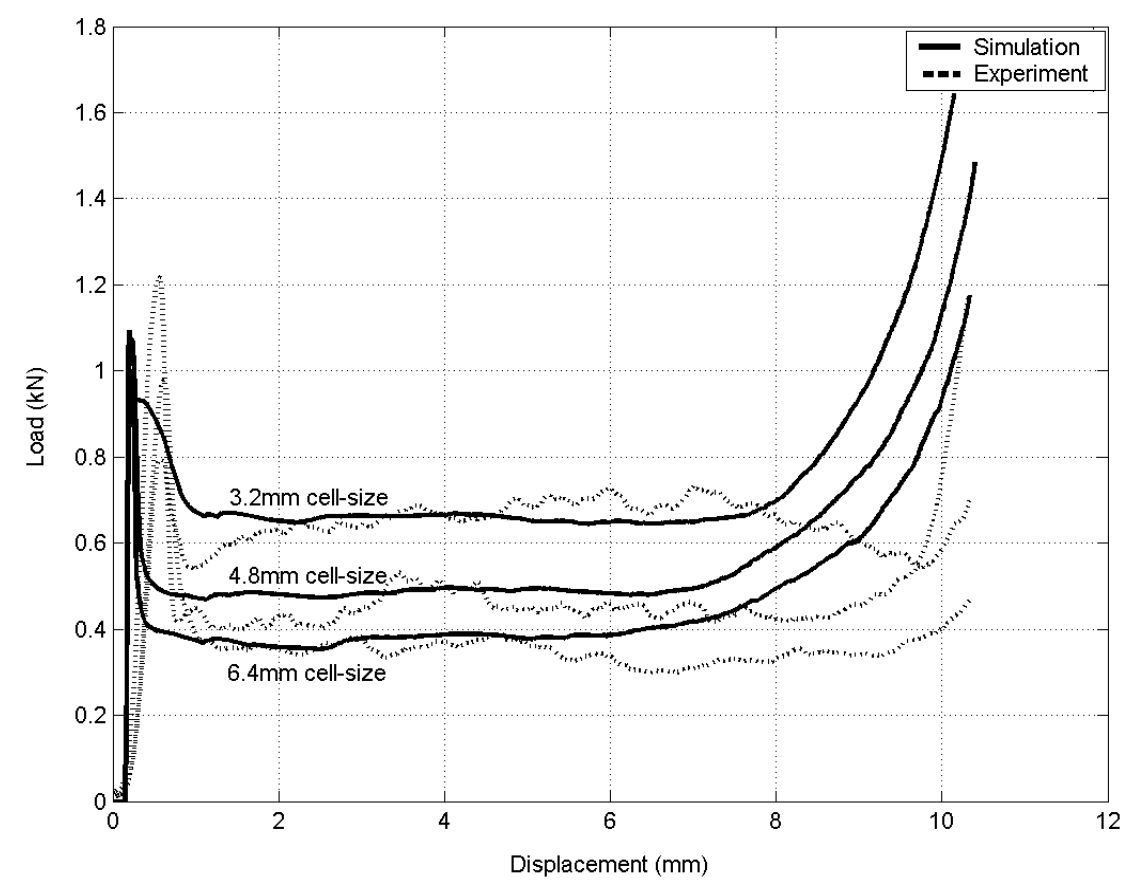

Fig. (3). Experimental and numerical quasi-static load-displacement curves of the honeycomb fillers.
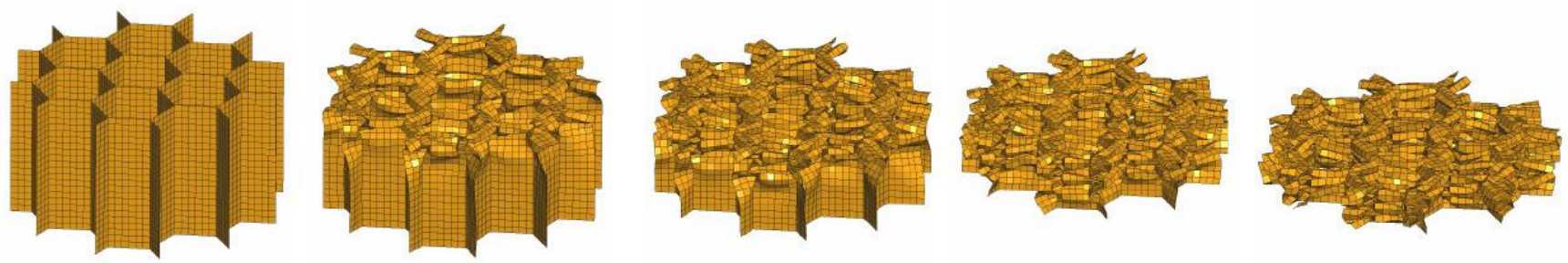

(a)
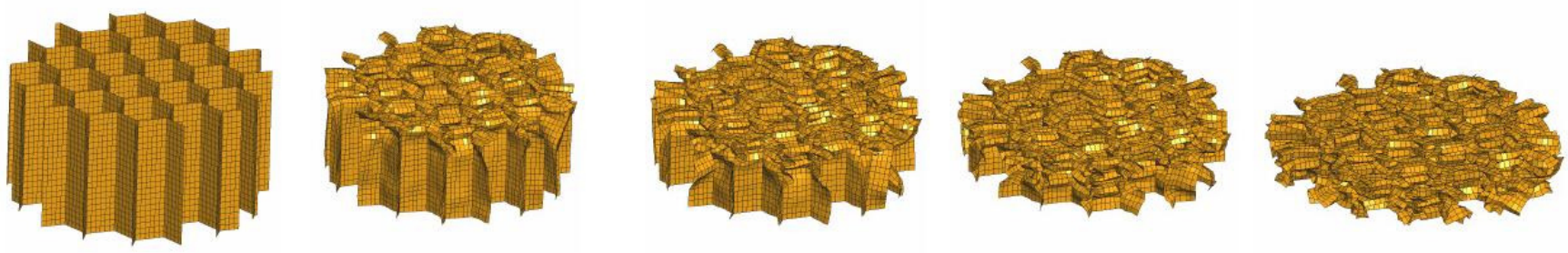

(b)
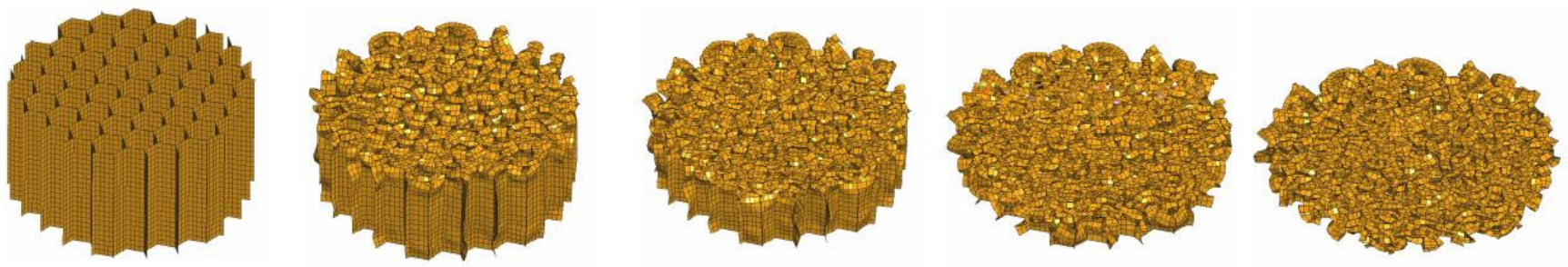

(c)

Fig. (4). Pictures of compressed (a) $6.4 \mathrm{~mm}$, (b) $4.8 \mathrm{~mm}$ and (c) $3.2 \mathrm{~mm}$ cell size honeycomb samples at $0 \%, 20 \%, 40 \%, 60 \% 80 \%$ percent strains (left to right).

thereafter the load decreases to lower values and shows fluctuations as the empty tube progressively deforms in diamond mode until densification region. Totally 5 folds formed both experimentally and numerically. At the densification region, numerical models reach higher load values due to the contacts between the neighbouring folds. 

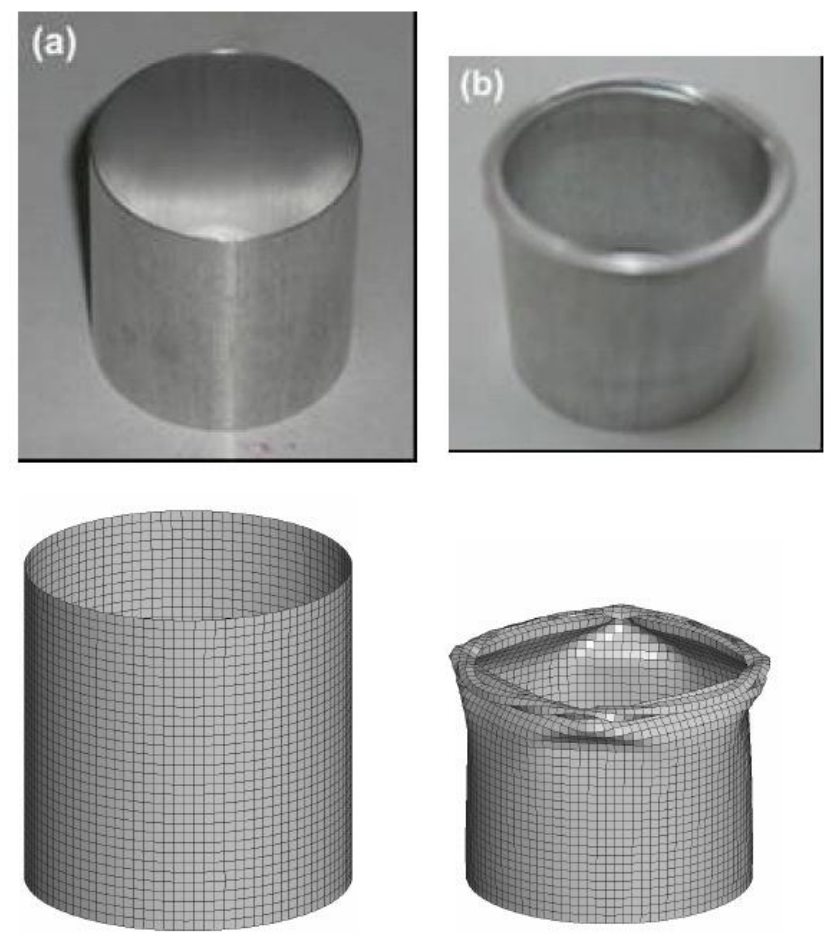
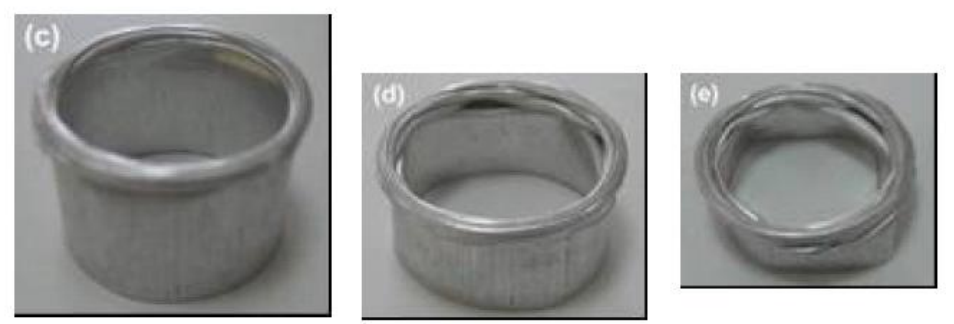

(a)
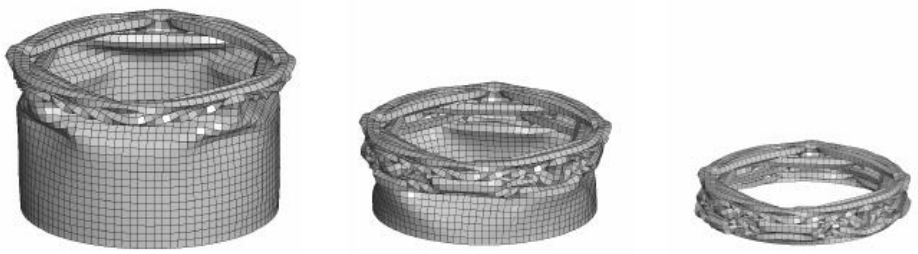

(b)

Fig. (5). Pictures of compressed empty tubes at $0 \%, 20 \%, 40 \%, 60 \%$ and $80 \%$ percent strains (left to right); (a) experimental and (b) numerical.

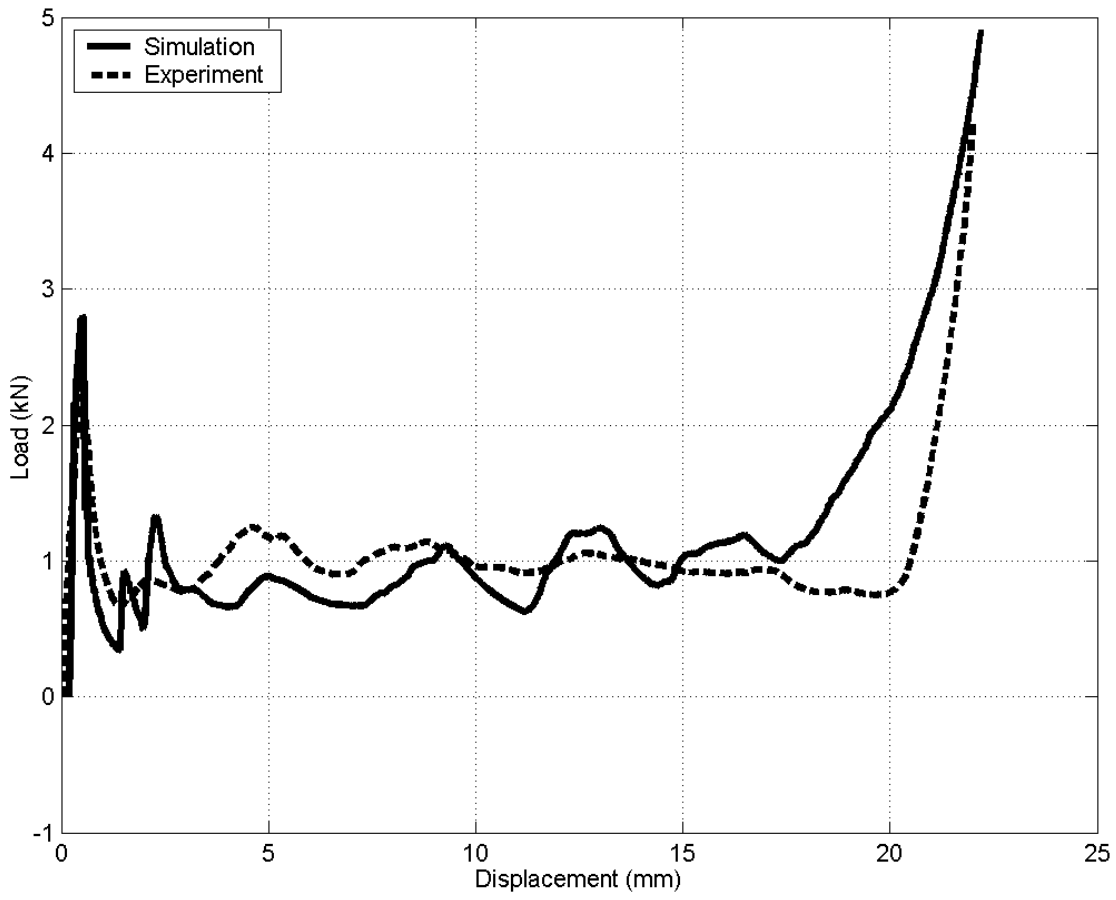

Fig. (6). Experimental and numerical load-displacement curve of the empty tube.

The variations in the thickness of the phenolic resin lead to variations in the cell wall thicknesses.

In order to determine the effect of cell wall thickness on the load-displacement curves, the simulations were performed with the honeycomb filler of $0.10 \mathrm{~mm}$ and 0.13 $\mathrm{mm}$ cell wall thicknesses. The weight of the numerical honeycomb models, for both $0.10 \mathrm{~mm}$ and $0.13 \mathrm{~mm}$ wall thicknesses, and the real specimens were further compared. The weight difference was found $\pm 10 \%$, confirming that the average cell wall thickness varied between $0.10 \mathrm{~mm}$ and 0.13 $\mathrm{mm}$.

The numerical deformed shapes of $6.4 \mathrm{~mm}, 4.8 \mathrm{~mm}$ and $3.2 \mathrm{~mm}$ cell size honeycomb-filled Al tubes at various percent deformations are shown sequentially in Figs. (7a-c, 

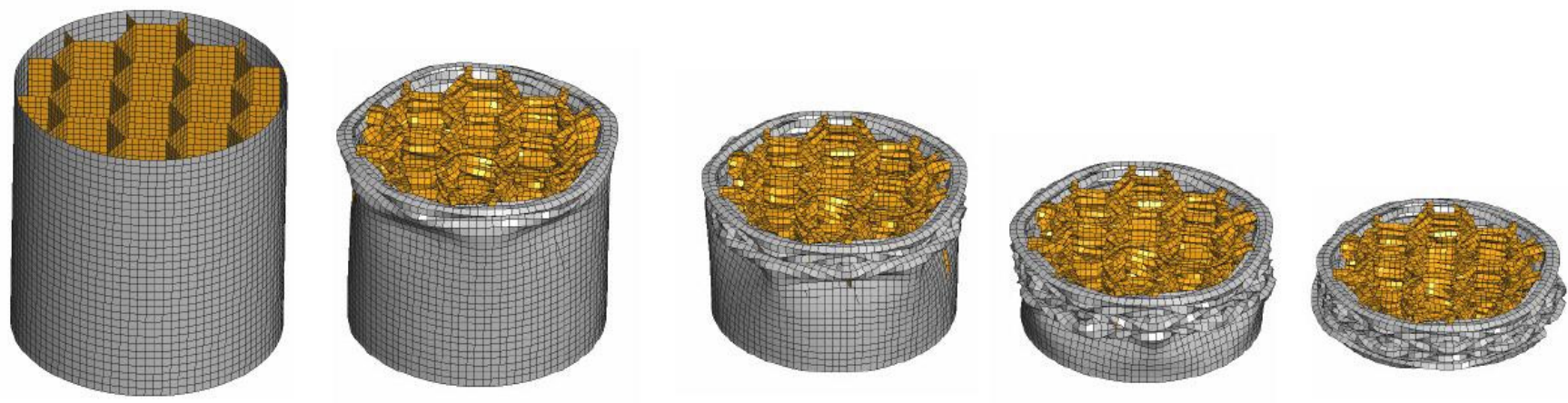

(a)
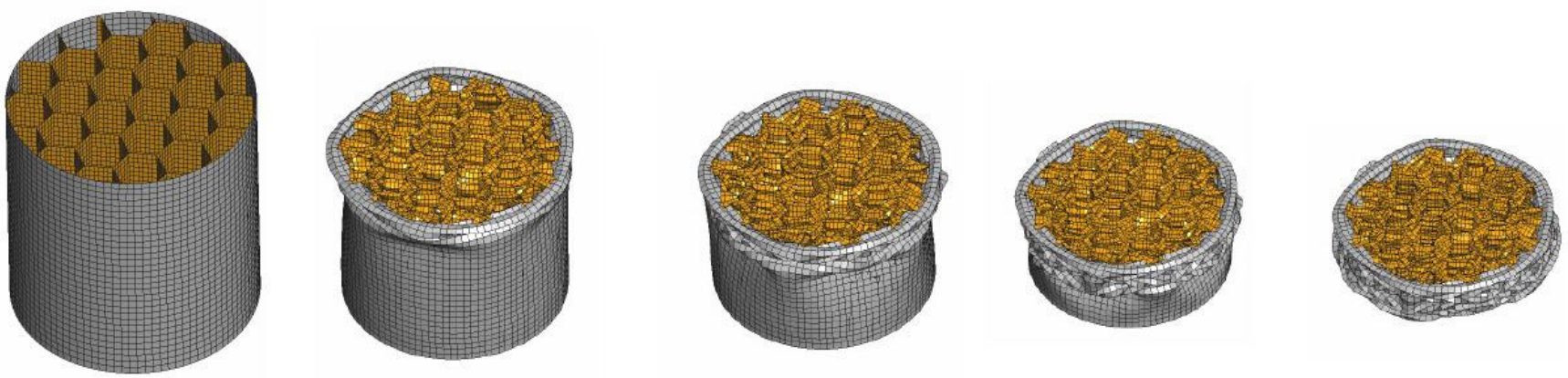

(b)
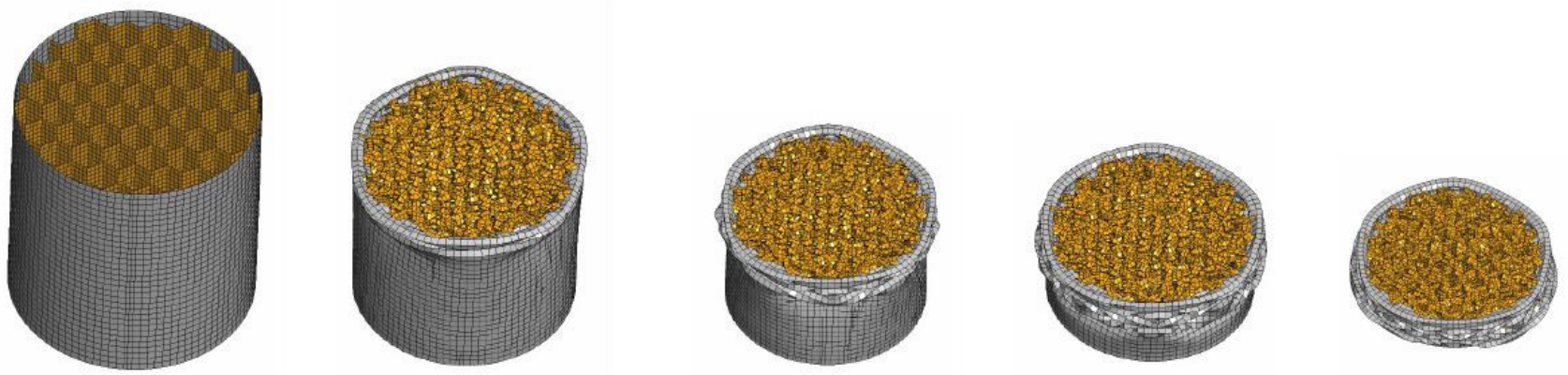

(c)

Fig. (7). Pictures of compressed (a) $6.4 \mathrm{~mm}$, (b) $4.8 \mathrm{~mm}$ and (c) $3.2 \mathrm{~mm}$ cell size ( $\mathrm{t}=0.10 \mathrm{~mm}$ ) honeycomb-filled tubes at $0 \%$, 20\%, 40\%, $60 \%$ and $80 \%$ strains (left to right).

8a-c) for $0.10 \mathrm{~mm}$ and $0.13 \mathrm{~mm}$ wall thicknesses, respectively.

The experimental deformed shapes of $6.4 \mathrm{~mm}, 4.8 \mathrm{~mm}$ and $3.2 \mathrm{~mm}$ cell size honeycomb-filled Al tubes at various percent deformations are further shown sequentially in Fig. (9a-c). The numerical model highlighted several deformation features of the experimentally observed progressive crushing mechanisms. For both wall thicknesses, the deformed shapes of the honeycomb-filled tubes are almost the same. Although, $6.4 \mathrm{~mm}$ and $4.8 \mathrm{~mm}$ cell size honeycomb-filled tubes show diamond mode of deformation following the initial axisymmetric fold, $3.2 \mathrm{~mm}$ cell size honeycomb-filled tube shows concertina and/or mixed mode of deformation pattern (Fig. 9a-c).

The similar deformation patterns are also found in numerical deformations of the filled tubes. Fig. (10a-c) compare the numerical and experimental load-displacements curves of $6.4 \mathrm{~mm}, 4.8 \mathrm{~mm}$ and $3.2 \mathrm{~mm}$ cell size honeycombfilled tubes, respectively.

As is expected, the thicker cell walls $(0.13 \mathrm{~mm})$ results in higher load levels than those of thinner cell walls $(0.10 \mathrm{~mm})$. As noted in Fig. (10a-c), the numerical initial peak-load values are higher than those of experiments. This was attributed to the triggering effect of the glued-surfaces of two 

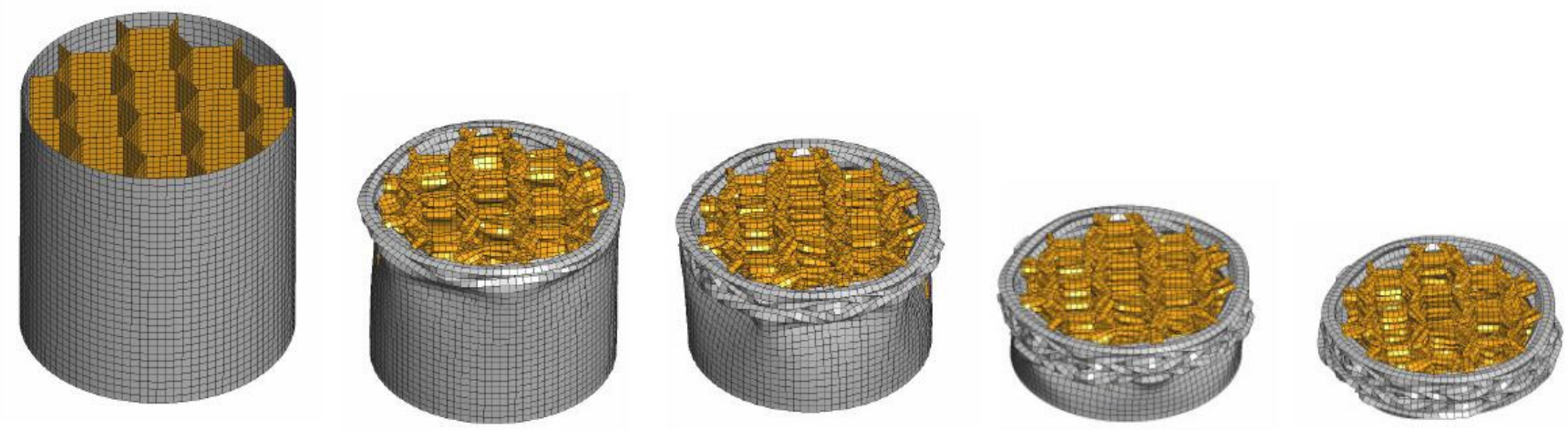

(a)
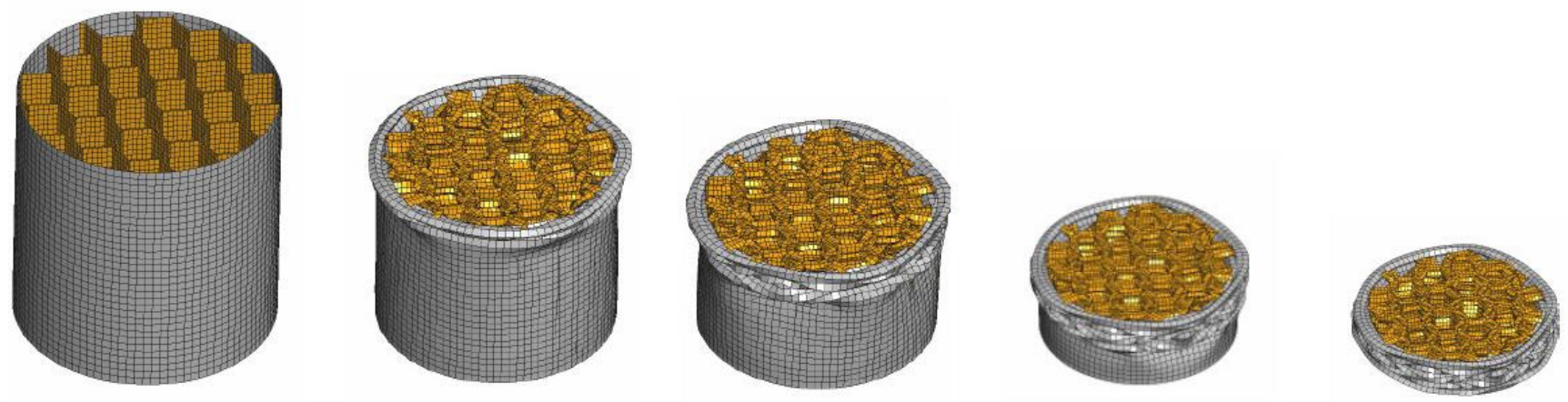

(b)
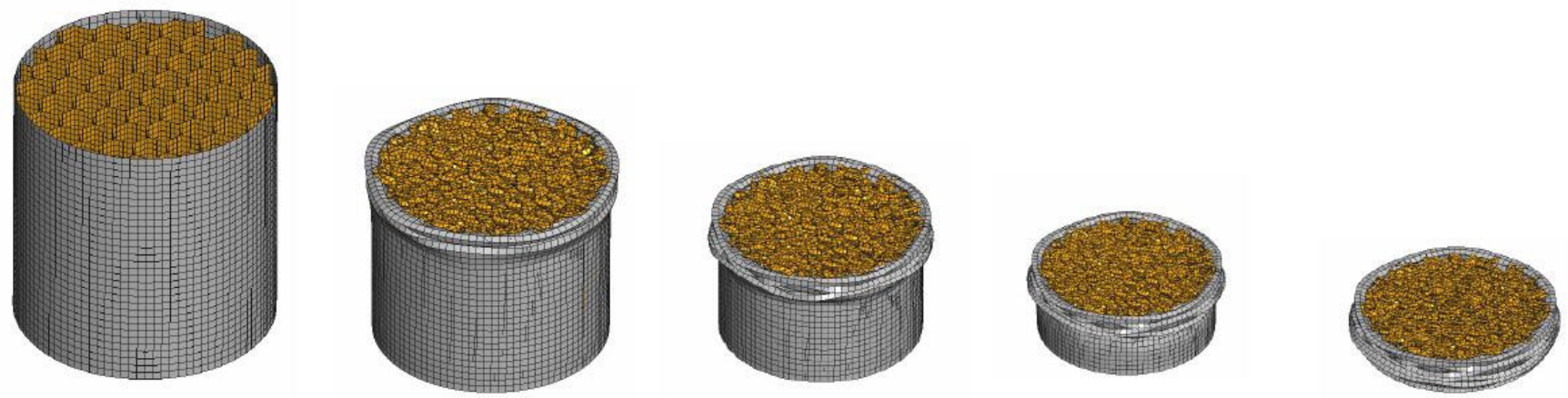

(c)

Fig. (8). Pictures of compressed (a) $6.4 \mathrm{~mm}$, (b) $4.8 \mathrm{~mm}$ and (c) $3.2 \mathrm{~mm}$ cell size ( $\mathrm{t}=0.13 \mathrm{~mm}$ ) honeycomb-filled tubes at $0 \%, 20 \%, 40 \%$, $60 \%$ and $80 \%$ strains (left to right).

honeycomb layers in the filled tubes which was not present in the numerical model. The numerical and experimental load values further show good agreements for $6.4 \mathrm{~mm}$ cell size honeycomb-filled tubes, while numerical loaddisplacement curves of $4.8 \mathrm{~mm}$ cell size and $3.2 \mathrm{~mm}$ cell size honeycomb-filled tubes are higher than those of experiments as shown in Fig. $(\mathbf{1 0 b}, \mathbf{c})$. However, the differences between numerical and experimental load-displacement curves of 3.2 $\mathrm{mm}$ cell size honeycomb-filled tube are more pronounced particularly near and after the densification region. This may arise partly from an effect of the self-contact thickness since the higher number of the elements used in the numerical self contact algorithm may produce higher crushing loads than experiments. This effect will be further investigated. Lastly, the number of folds formed in numerical models and experiments are also very much similar in filled tubes: numerically 5,5 and 6 and experimentally 5, 5-6 and 6 folds formed in $6.4,4.8$ and $3.2 \mathrm{~mm}$ cell size honeycomb-filled tubes, respectively.

Fig. (11a-c) show sequentially the cross-sections of the partially deformed $6.4,4.8$ and $3.2 \mathrm{~mm}$ cell size honeycombfilled tubes. It was noted that the triggering started from the glued sections of the filler in fewer samples as shown in Fig. (11b). However, the filler and tube deformation are generally progressive and triggers from one of the ends of the filled tube as seen in Fig. (11a, b). Furthermore, even the same 
(a)

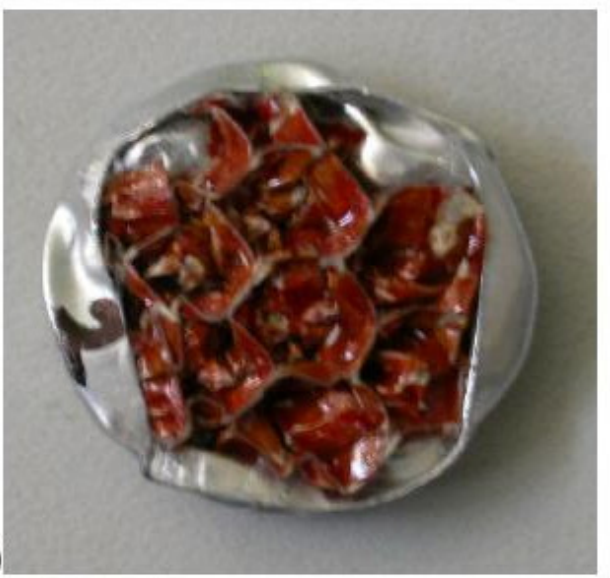

(b)

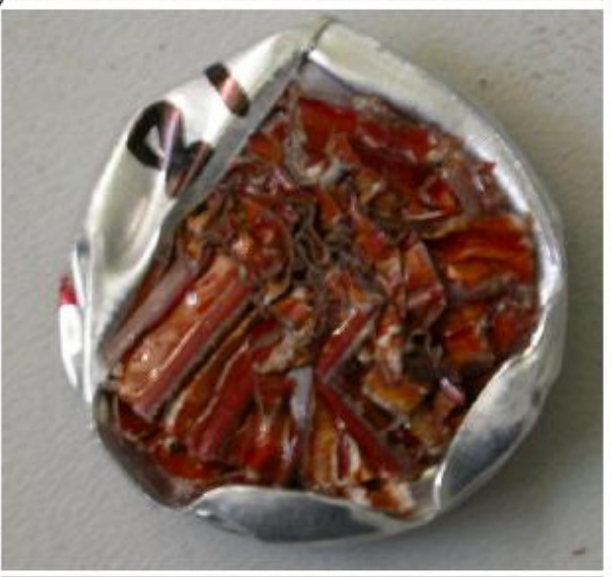

(c)

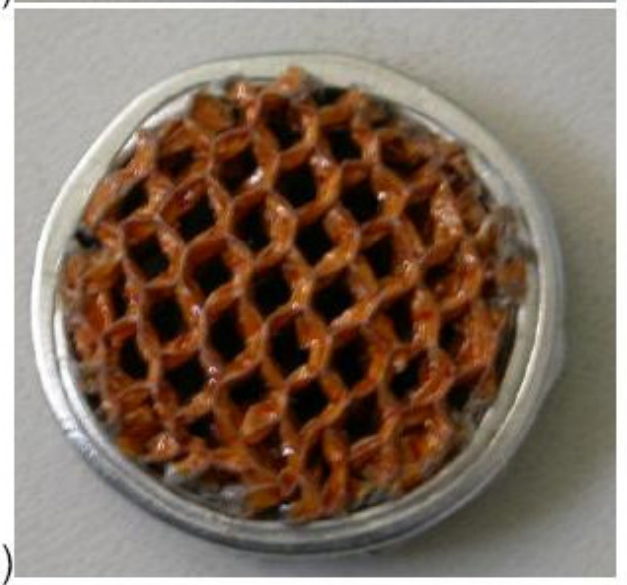

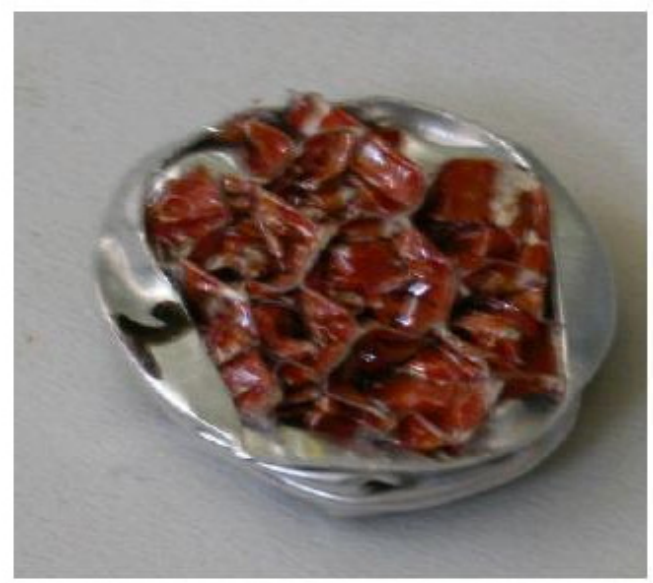
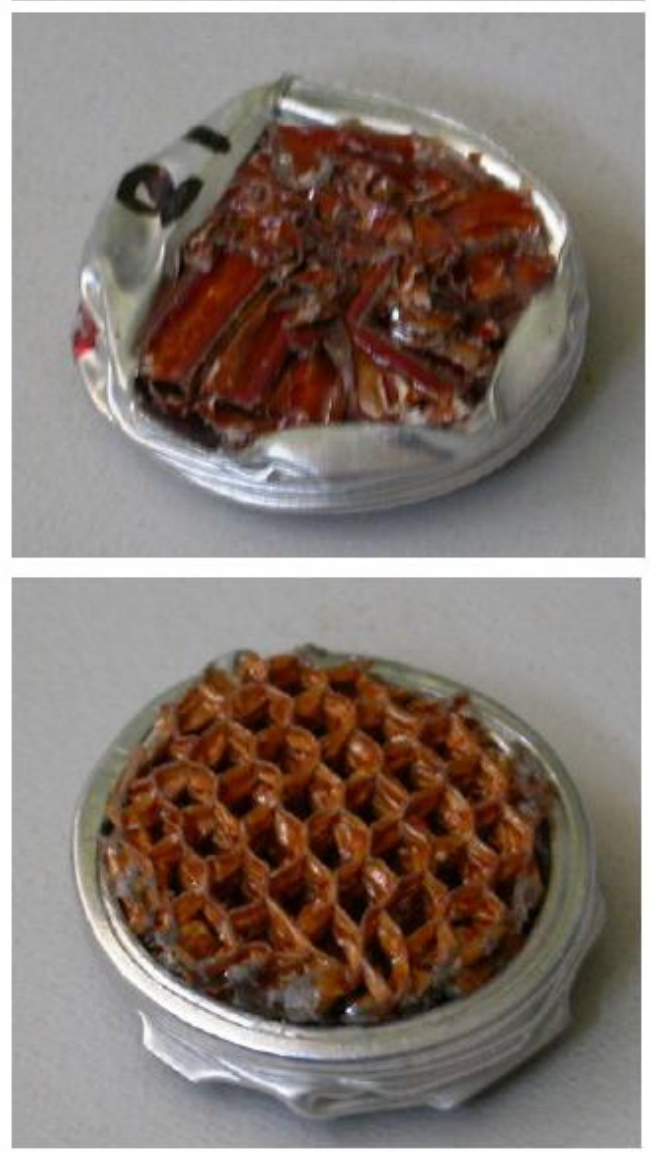

Fig. (9). Pictures of experimentally deformation filled tubes: (a) $6.4 \mathrm{~mm}$, (b) $4.8 \mathrm{~mm}$ and (c) $3.2 \mathrm{~mm}$ cell size honeycomb-filled tubes.

series of honeycomb specimens are expected to show small variations in the number of cells, cell size and cell wall thickness distribution, leading to discrepancies between individual tests and experimental and numerical results.

The experimental and numerical SAE values corresponding to $50 \%$ and $80 \%$ deformation of empty and honeycomb-filled tubes are summarized in Table 1. The maximum discrepancy between numerical and experimental SAE values is below $20 \%$. As tabulated in Table $1,3.2 \mathrm{~mm}$ cell size honeycomb-filled tubes exhibit the highest SAE values for both cell wall thicknesses studied. $3.2 \mathrm{~mm}$ cell size honeycomb-filled tubes with $0.13 \mathrm{~mm}$ wall thickness result in lower SAE values than those of $0.10 \mathrm{~mm}$ wall thicknesses. At $50 \%$ and $80 \%$ deformation strains, honeycomb fillings are energetically more efficient than empty tube. In order to check whether the honeycomb filling is efficient against the tube wall thickening, the SAE values of the cell wall thickening of empty tubes were simulated and the results are tabulated in Table $2.3 .2 \mathrm{~mm}$ cell size honeycomb-filled tubes show higher SAE than the empty tube with two times thicker wall thickness, which is in accord with the study of Wierzbicki and Santosa [3, 4]. When the tube wall thickness is increased to the three times of the initial empty tube wall thickness, the honeycomb filling becomes inefficient. This result should be used as a design criterion in honeycomb filling of cylindrical tubes. The SAE values of honeycomb filling are further compared 

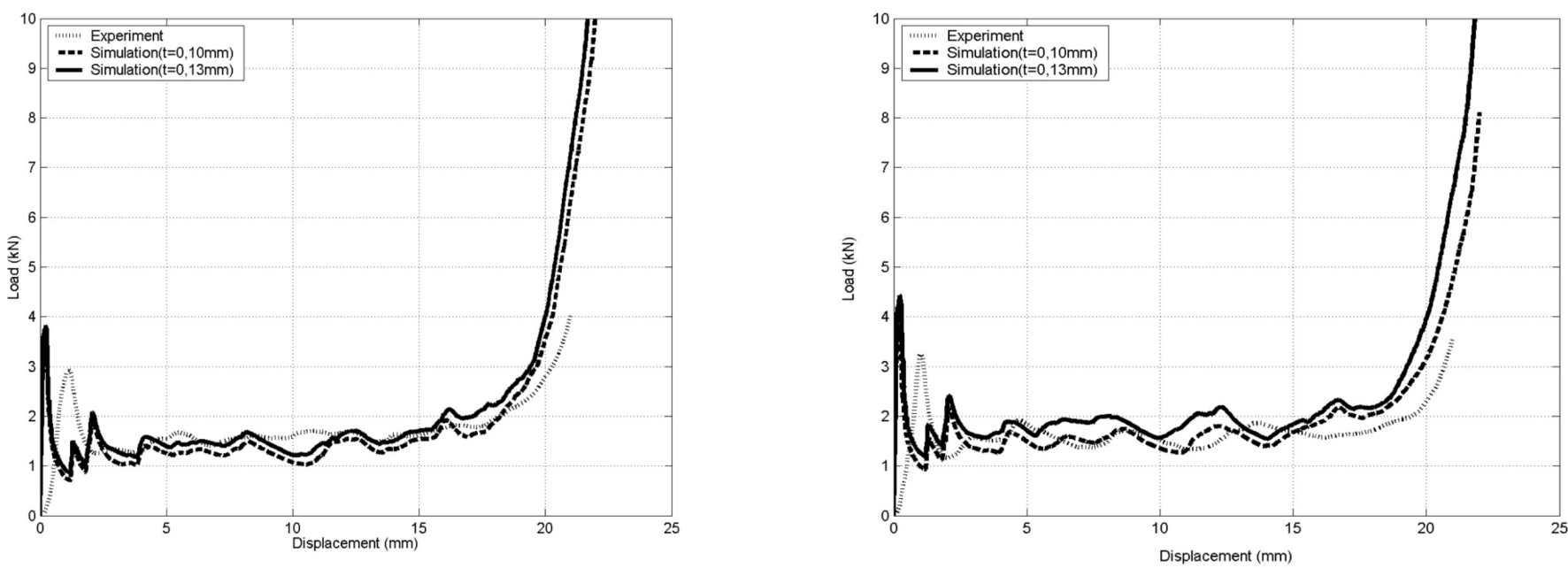

a)

b)

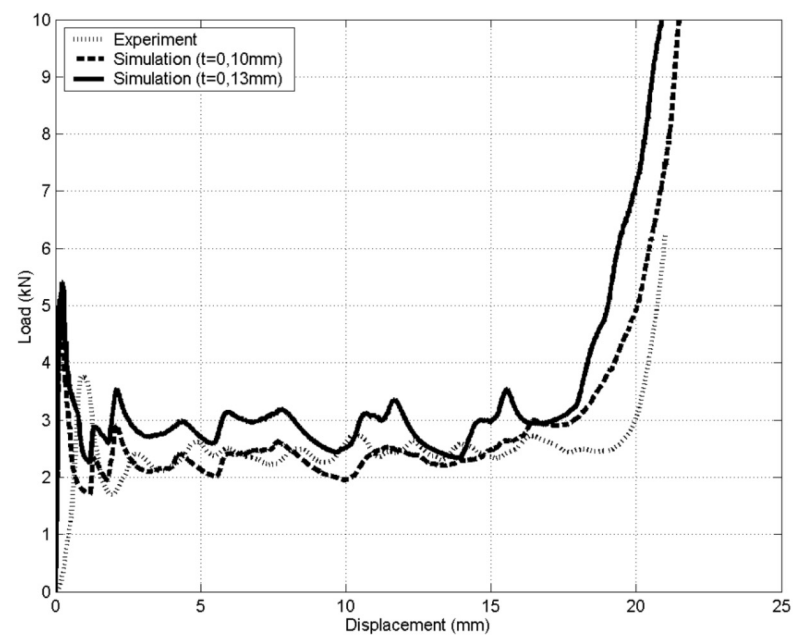

c)

Fig. (10). Experimental and numerical load-displacement curves of a) $6.4 \mathrm{~mm}$, b) $4.8 \mathrm{~mm}$ and c) $3.2 \mathrm{~mm}$ cell size honeycomb-filled tubes.

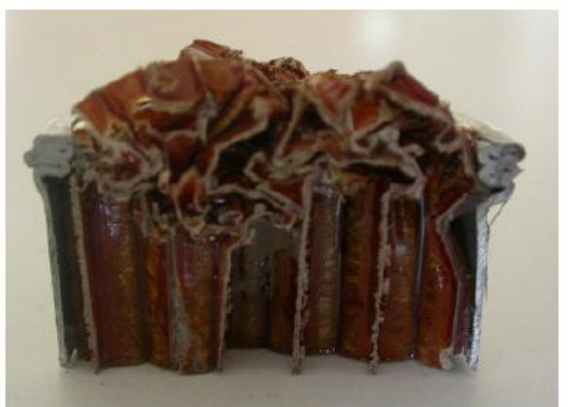

a)

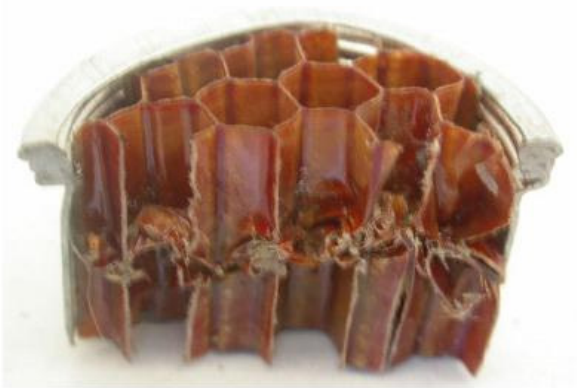

b)

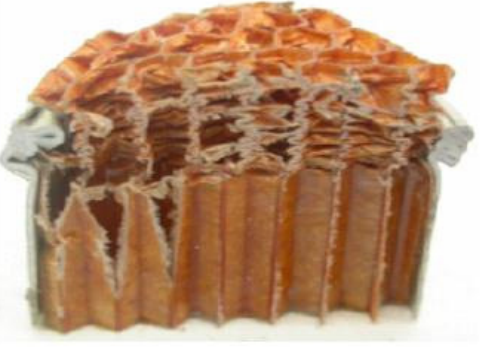

c)

Fig. (11). Cross-sectional view of a) $6.4 \mathrm{~mm}$, b) $4.8 \mathrm{~mm}$ and c) $3.2 \mathrm{~mm}$ cell size honeycomb-filled tubes.

with those of Al closed-cell foams $\left(0.27,0.35\right.$ and $0.42 \mathrm{~g} \mathrm{~cm}^{-}$ ${ }^{3}$ ) filling of the same Al tube, which was previously studied [10]. The $3.2 \mathrm{~mm}$ cell size honeycomb-filled Al tube shows higher SAE values than $\mathrm{Al}$ foam-filled tubes at $50 \%$ deformation. It has higher SAE values than $0.27 \mathrm{~g} \mathrm{~cm}^{-3}$ $\left(13.17 \mathrm{~kJ} \mathrm{~kg}^{-1}\right)$ foam filling and similar SAE values with 0.35 $\mathrm{g} \mathrm{cm}^{-3}\left(16.78 \mathrm{~kJ} \mathrm{~kg}^{-1}\right)$ foam filling at $80 \%$ deformation. These results further confirm that, similar to Al foam-filled tubes, there exists a critical cell size/density of honeycomb above which the filling becomes more efficient than tubewall thickening.

\section{CONCLUSIONS}

In this study, the experimental and numerical quasi-static crushing behavior of 3.2, 4.8 and $6.4 \mathrm{~mm}$ cell size Nomex ${ }^{\mathrm{TM}}$ honeycomb-filled thin-walled Al tubes was investigated. The 
Table 1. SAE Values Empty and Filled Tubes at 50 and $80 \%$ Deformation

\begin{tabular}{|l|l|l|}
\hline \multicolumn{1}{|c|}{ Design } & SAE at 50\% $\left(\mathbf{k J ~ k g}^{-\mathbf{1}}\right)$ & SAE at 80\% $\left(\mathbf{k J} \mathbf{~ g g}^{-1}\right)$ \\
\hline \hline Empty Tube (Experimental) & 7.88 & 12.04 \\
\hline Empty Tube (Numerical) & 6.31 & 10.43 \\
\hline $3.2 \mathrm{~mm}$ cell size honeycomb-filled (Experimental) & 9.68 & 16.00 \\
\hline $3.2 \mathrm{~mm}$ cell size honeycomb-filled (Numerical, $\mathrm{t}=0.10 \mathrm{~mm})$ & 9.42 & 16.67 \\
\hline $3.2 \mathrm{~mm}$ cell size honeycomb-filled (Numerical, $\mathrm{t}=0.13 \mathrm{~mm})$ & 9.14 & 15.86 \\
\hline $4.8 \mathrm{~mm}$ cell size honeycomb-filled (Experimental) & 7.98 & 13.58 \\
\hline $4.8 \mathrm{~mm}$ cell size honeycomb-filled (Numerical, $\mathrm{t}=0.10 \mathrm{~mm})$ & 6.92 & 12.31 \\
\hline $4.8 \mathrm{~mm}$ cell size honeycomb-filled (Numerical, $\mathrm{t}=0.13 \mathrm{~mm})$ & 6.44 & 11.10 \\
\hline $6.4 \mathrm{~mm}$ cell size honeycomb-filled (Experimental) & 8.11 & 14.12 \\
\hline $6.4 \mathrm{~mm}$ cell size honeycomb-filled (Numerical, $\mathrm{t}=0.10 \mathrm{~mm})$ & 7.74 & 14.47 \\
\hline $6.4 \mathrm{~mm}$ cell size honeycomb-filled (Numerical, $\mathrm{t}=0.13 \mathrm{~mm})$ & 6.75 & 12.64 \\
\hline
\end{tabular}

honeycomb filler was modeled using unit cell model. In order to show the extent of crushing load dependency of the filled tubes on the cell wall thickness of honeycomb, tubes filled with $0.10 \mathrm{~mm}$ and $0.13 \mathrm{~mm}$ cell wall thickness honeycombs were simulated. The experimental and numerical results have shown that $6.4 \mathrm{~mm}$ and $4.8 \mathrm{~mm}$ cell size honeycomb filling had no effect on the deformation mode of empty tube (diamond), while $3.2 \mathrm{~mm}$ cell size honeycomb filling changed the tube deformation mode into mixed/concertina. Honeycomb filling was shown, both experimentally and numerically, to increase SAE values of Al tubes. It was further shown that the smallest cell size honeycomb filling was more efficient until about two times increases in the thickness of empty tube. Compared with Al foam filling, smaller size cell size honeycomb filling was found to be more weight efficient until about moderate deformations.

Table 2. SAE Values of Wall Thickening of Empty Tubes at 50 and $80 \%$ Deformation

\begin{tabular}{|c|c|c|}
\hline Design & $\begin{array}{c}\text { SAE at 50\% } \\
\left(\mathbf{k J ~ k g}^{-1}\right) \\
(\mathbf{N u m e r i c a l})\end{array}$ & $\begin{array}{c}\text { SAE at 80\% } \\
\left(\mathbf{k J ~ k g} \mathbf{~ g}^{-1}\right) \\
(\mathbf{N u m e r i c a l})\end{array}$ \\
\hline \hline Empty tube & 6.31 & 10.43 \\
\hline Empty tube (two times thicker) & 8.98 & 14.30 \\
\hline Empty tube (three times thicker) & 11.45 & 20.11 \\
\hline
\end{tabular}

\section{ACKNOWLEDGEMENTS}

The authors thank the Scientific and Technical Council of Turkey (TUBITAK) for the Grant \#MISAG-227 and Mr.
Carlo Schaffner from Euro-Composites for supplying the honeycomb specimens and Ms. Parya Naghipour from German Aerospace Center, Institute of Structures and Design (currently at the Institute of Materials Research, Cologne) for writing the APDL-based honeycomb generator code.

\section{REFERENCES}

[1] Alexander JM. An approximate analysis of collapse of thin-walled cylindrical shells under axial loading, Q. J. Mech Appl Math 1960; 13: $1-9$.

[2] Aktay L, Toksoy AK, Güden M. Quasi-static axial crushing of extruded polystyrene foam-filled thin-walled aluminum tubes: experimental and numerical analysis. Mater Des 2006; 27: 556-65.

[3] Santosa S, Wierzbicki T. Crash behavior of box columns filled with aluminum honeycomb or foam. Comput Struct 1998; 68: 343-67.

[4] Wierzbicki T, Santosa S. Effect of an ultralight metal filler on the bending collapse behavior of thin-walled prismatic columns. Int $\mathrm{J}$ Mech Sci 1999; 41: 995-1019.

[5] Santosa S, Wierzbicki T. The concept of double-walled sandwich columns for energy absorption. Int J Crashworth 1999; 4(2): 17597.

[6] Zarei H, Kröger M. Optimum honeycomb filled crash absorber design. Mater Des 2008; 29: 193-204.

[7] Heimbs S. Virtual testing of sandwich core structures using dynamic finite element simulations. Comput Mater Sci 2009; 45(2): 205-16.

[8] Hill R. A theory of the yielding and plastic flow of anisotropic metals, Proc Roy Soc London 1948; 193: 281-97.

[9] Benson D, Hallquist J. A single surface contact algorithm for the post-buckling analysis of shell structures. Comp Methods Appl Mech Engrg 1990; 78: 141-63.

[10] Aktay L, Kröplin B-H, Toksoy AK, Güden M, Finite element and coupled finite element/smooth particle hydrodynamics modeling of the quasi-static crushing of empty and foam-filled single, bitubular and constraint hexagonal- and square-packed aluminum tubes. Mater Des 2008; 29(5): 952-62. 